\title{
Induction of apoptosis of human primary osteoclasts treated with extracts from the medicinal plant Emblica officinalis
} Letizia Penolazzi ${ }^{1}$, Ilaria Lampronti ${ }^{1}$, Monica Borgatti ${ }^{1}$, Mahmud Tareq Hassan Khan ${ }^{2,3}$, Margherita Zennaro ${ }^{1}$, Roberta Piva ${ }^{1}$ and Roberto Gambari*1,4

Address: ${ }^{1}$ BioPharmaNet, ER-GenTech, Department of Biochemistry and Molecular Biology, Ferrara University, Ferrara, Italy, ${ }^{2}$ Department of Pharmacology, Institute of Medical Biology, University of Tromso, Tromso, Norway, ${ }^{3}$ H.E.J. Research Institute of Chemistry, International Center for Chemical Sciences, University of Karachi, Karachi, Pakistan and ${ }^{4}$ Biotechnology Center, Ferrara University, Ferrara, Italy

Email: Letizia Penolazzi - pnlmlt@unife.it; Ilaria Lampronti - Imi@unife.it; Monica Borgatti - brgmnc@unife.it; Mahmud Tareq Hassan Khan - mahmud.khan@fagmed.int.no; Margherita Zennaro - znnmgh@unife.it; Roberta Piva - piv@unife.it; Roberto Gambari* - gam@unife.it

* Corresponding author

Published: 30 October 2008

BMC Complementary and Alternative Medicine 2008, 8:59 doi:10.1 186/1472-6882-8-59

This article is available from: http://www.biomedcentral.com/I472-6882/8/59

(c) 2008 Penolazzi et al; licensee BioMed Central Ltd.

This is an Open Access article distributed under the terms of the Creative Commons Attribution License (http://creativecommons.org/licenses/by/2.0), which permits unrestricted use, distribution, and reproduction in any medium, provided the original work is properly cited.

\begin{abstract}
Background: Osteoclasts (OCs) are involved in rheumatoid arthritis and in several pathologies associated with bone loss. Recent results support the concept that some medicinal plants and derived natural products are of great interest for developing therapeutic strategies against bone disorders, including rheumatoid arthritis and osteoporosis. In this study we determined whether extracts of Emblica officinalis fruits display activity of possible interest for the treatment of rheumatoid arthritis and osteoporosis by activating programmed cell death of human primary osteoclasts.
\end{abstract}

Methods: The effects of extracts from Emblica officinalis on differentiation and survival of human primary OCs cultures obtained from peripheral blood were determined by tartrate-acid resistant acid phosphatase (TRAP)positivity and colorimetric MTT assay. The effects of Emblica officinalis extracts on induction of OCs apoptosis were studied using TUNEL and immunocytochemical analysis of FAS receptor expression. Finally, in vitro effects of Emblica officinalis extracts on NF-kB transcription factor activity were determined by gel shift experiments.

Results: Extracts of Emblica officinalis were able to induce programmed cell death of mature OCs, without altering, at the concentrations employed in our study, the process of osteoclastogenesis. Emblica officinalis increased the expression levels of Fas, a critical member of the apoptotic pathway. Gel shift experiments demonstrated that Emblica officinalis extracts act by interfering with NF-kB activity, a transcription factor involved in osteoclast biology. The data obtained demonstrate that Emblica officinalis extracts selectively compete with the binding of transcription factor NF-kB to its specific target DNA sequences. This effect might explain the observed effects of Emblica officinalis on the expression levels of interleukin-6, a NF-kB specific target gene.

Conclusion: Induction of apoptosis of osteoclasts could be an important strategy both in interfering with rheumatoid arthritis complications of the bone skeleton leading to joint destruction, and preventing and reducing osteoporosis. Accordingly, we suggest the application of Emblica officinalis extracts as an alternative tool for therapy applied to bone diseases. 


\section{Background}

Osteoclasts (OCs) are multinucleated cells of hematopoietic origin and are the primary bone resorbing cells [1-4]. There is increasing evidence that OCs play a crucial role in bone loss in rheumatoid arthritis [5-9], as recently reported by Ochi et al. [5] and reviewed by several authors, including Schett [6], Haynes [7], Tremoulet and Albani [8], Boyce et al. [9], Sato and Takayanagi [10] and Teitelbaum [11]. Abundant osteoclasts are found within the synovial tissue at sites adjacent to bone, creating resorption pits and local bone destruction followed by degradation of the bone matrix and calcium solubilization [6]. The basis of this behavior is that the synovial tissue of inflamed joints harbor high concentrations of monocytes/macrophages, which are osteoclast precursors, as well as cells that provide the specific molecular signals that drive osteoclast formation [6]. For instance, human rheumatoid synovial lymphocytes and fibroblasts promote osteoclastogenic activity by activating the receptor activator of NF-kB ligand (RANKL). The cytokines involved in this process are well known and have been the object of several studies $[12,13]$, pointing out that TNF $\alpha$, and IL-7 are involved in OCs differentiation [13]. Osteoclasts thus represent a link between joint inflammation and structural damage [6]. Hence, therapeutic approaches inhibiting osteoclastogenesis have been proposed by several authors for rheumatoid arthritis therapy [14-20].

These drugs are also expected to be of interest in the therapy of other pathologies associated with bone loss, such as osteoporosis [21-23] and bone metastasis [24-27], as inhibition of bone resorption, aimed at preventing further bone loss, is based on the efficient targeting of OCs function [21-27]. In conclusion, several therapeutic approaches are based on inhibition of osteoclast-dependent bone resorption through inhibition of OCs differentiation or stimulation of OCs apoptosis.

Recent results support the concept that some medicinal plants and natural products derived from them are of great interest for developing therapeutic strategies against bone disorders, including rheumatoid arthritis and osteoporosis [28-33]. Yin J. et al. demonstrated that water extracts of Dioscorea spongiosa stimulate osteoblasts proliferation, exhibiting at the same time a potent inhibitory activity on osteoclastogenesis [34]. Fruit extracts of Psoralea corylifolia [35] and Cnidium monnieri [36] have been shown to exhibit osteoblastic proliferation stimulating activity in osteoblast-like UMR106 cells in vitro. Several plant extracts inhibiting OCs differentiation also display strong anti-inflammatory properties [34-36].

Emblica officinalis is certainly a medicinal plant of interest [37-45]. It has played an important medicinal role for centuries in the Indian system of medicine. Fruits of E. offici- nalis are used for the treatment of a number of diseases, such as dyslipidemia [37] and atherosclerosis [38], as hepatoprotective [39], antibacterial [40] and anti-inflammatory agent [41]. In many cases, E. officinalis has been shown to be a potent free radical scavenging agent thereby preventing carcinogenesis and mutagenesis [42].

In this study we investigated whether extracts of Emblica officinalis fruits display effects of possible interest for the treatment of rheumatoid arthritis and osteoporosis, by activating programmed cell death of human primary osteoclasts. The effects of E. officinalis on human osteoclasts obtained from peripheral blood mononuclear cells $[46,47]$ were analyzed by determining the proportion of apoptotic OCs. The effects of Emblica officinalis extracts were studied also on NF-kB/DNA interactions by electrophoretic mobility shift assay [48], given the possible involvement of the NF-kB transcription factor on the maintenance of the differentiation program of osteoclasts [49-51]. The effects of Emblica officinalis extracts on the expression of NF-kB dependent genes were also determined.

\section{Methods}

\section{Culture of human primary osteoclasts}

Human OCs were prepared as reported by Mitsuzaki et al. [52] with slight modifications. Peripheral blood was collected from healthy normal volunteers after informed consent. Mononuclear cells (PBMCs) were prepared from diluted peripheral blood (1:2 in Hanks Balanced Salt Solution), which was layered over Histopaque 1077 (Sigma, St. Louis, MO, USA) solution, centrifuged (400 g), washed and suspended in D-MEM/10\% FCS. $3 \times 10^{6}$ PBMCs $/ \mathrm{cm}^{2}$ were plated in 24-well plates or in chamber slides and allowed to settled for 2 hours. Wells were then rinsed to remove non-adherent cells. Monocytes were maintained at $37^{\circ} \mathrm{C}$, in $5 \% \mathrm{CO}_{2}$, in medium supplemented with $10 \%$ FCS and cultured for 14 days in the presence of human M-CSF ( $25 \mathrm{ng} / \mathrm{ml}$ ), RANKL ( $30 \mathrm{ng} / \mathrm{ml}$ ) and $10^{-7} \mathrm{M}$ PHT. Culture media were replenished with fresh media every 3-4 days. Cells were used for the described experiments when mature multinuclear cells were predominant in the cultures.

\section{Tartrate-resistant acid phosphatase (TRAP) staining}

TRAP staining of the cells was performed as reported by Villanova et al. [53]. Cells were fixed in 3\% para-formaldehyde with $0.1 \mathrm{M}$ cacodilic buffer, $\mathrm{pH} 7.2(0.1 \mathrm{M}$ Sodium cacodilate, $0.0025 \% \mathrm{CaCl}_{2}$ ) for $15 \mathrm{~min}$, extensively washed in the same buffer, and stained for TRAP (Acid Phosphatase Kit n. 386 - Sigma, St. Louis, MO, USA). After washing with distilled water and drying, mature TRAP positive multinucleated cells containing more than three nuclei were considered as osteoclasts. 


\section{Plant extracts}

The dried fruits of Emblica officinalis were extracted with absolute ethanol and the yield was $9.33 \%$. The chemical composition has been determined by GC/MS and was reported elsewhere $[54,55]$.

\section{Electrophoretic mobility shift assay (EMSA)}

Electrophoretic mobility shift assay (EMSA) was performed by using double stranded ${ }^{32} \mathrm{P}$-labelled oligonucleotides as target DNA [51]. Binding reactions were set up as described elsewhere in binding buffer (10\% glycerol, 0.05\% NP-40, 10 mM Tris- $\mathrm{HCl}$ pH 7.5, 50 mM NaCl, 0.5 $\mathrm{mM}$ DTT, $10 \mathrm{mM} \mathrm{MgCl} 2)$, in the presence of poly(dI:dC).poly(dI:dC) (Pharmacia, Uppsala, Sweden), $2 \mu \mathrm{g}$ of crude nuclear extracts and $0.25 \mathrm{ng}$ of labelled oligonucleotide, in a total volume of $20 \mu \mathrm{l}$ [28]. After $30 \mathrm{~min}$ binding at room temperature, samples were electrophoresed at constant voltage $(200 \mathrm{~V}$ for $1 \mathrm{hr})$ through a low ionic strength $(0.25 \times \mathrm{TBE}$ buffer $)(1 \times \mathrm{TBE}=0.089 \mathrm{M}$ Tris-borate, $0.002 \mathrm{M}$ EDTA) on $6 \%$ polyacrylamide gels until the tracking dye (bromophenol blue) reached the end of a $16 \mathrm{~cm}$ slab. Gels were dried and exposed for autoradiography with intensifying screens at $-80^{\circ} \mathrm{C}$. In these experiments, DNA/protein complexes migrate through the gel with slower efficiency. In studies on the inhibitors of protein/DNA interactions, the addition of the reagents was as follows: (a) poly(dI:dC).poly(dI:dC); (b) labelled oligonucleotides mimicking the binding sites for transcription factors to be analyzed; (c) plant extracts; (d) binding buffer; (e) nuclear factors. The nucleotide sequences of double-stranded target DNA utilized in these experiments were 5'-CGC TGG GGA CTT TCC ACG G-3' (sense strand, HIV-NF-kB binding site), and 5'-CTG ATT TCC CCG AAA TGA CGG-3' (sense strand, STAT-3 binding site).

\section{Measurement of apoptosis}

After 14 days of cell culture and 2-3 days of incubations with E. officinalis extracts, the cells were rinsed twice with PBS solution and fixed for $25 \mathrm{~min}$ in 4\% paraformaldehyde at room temperature. Apoptotic cells were detected by the DeadEnd Colorimetric Apoptosis Detection System (Promega) according to the manufacturer's instructions. Measurement of apoptosis was calculated as a percentage of apoptotic nuclei (dark brown nuclei) versus total nuclei of multinucleated TRAP positive cells, evaluated in three independent measurements. A dark brown DAB signal indicates positive staining, while shades of blue-green to greenish tan indicate a nonreactive cell $[46,47]$.

\section{Immunocytochemistry analysis}

Immunocytochemistry analysis was performed employing the streptavidin-biotin method using Ultraystain Polyvalent-HRP Immunostaining Kit. OCs grown in multichamber slides were fixed in $100 \%$ cold methanol, and permeabilized with (v/v) Triton X-100 (Sigma) in TBS (Tris-buffered saline). Cells were incubated in $3 \% \mathrm{H}_{2} \mathrm{O}_{2}$ and blocked with Super Block reagent (Ultraystain Polyvalent-HRP Immunostaining Kit). After the reaction with the primary antibodies, rabbit polyclonal antibodies of human origin (Santa Cruz Biotech) against MMP9, FAS receptor, IL-6, and NF-kB (2 $\mathrm{mg} / \mathrm{ml})$ were used accordingly to the manufacturer's protocols, at 1:500 (MMP9), 1:100 (FAS receptor), 1:800 (IL-6) and 1:800 (NF-kB) dilutions. Incubation was carried out at $4^{\circ} \mathrm{C}$ for $16 \mathrm{hr}$. Cells were then incubated at room temperature with antipolyvalent Biotinylated Antibody (Ultraystain PolyvalentHRP Immunostaining Kit). After rinsing in TBS, Streptavidin HRP (Ultraystain Polyvalent-HRP Immunostaining Kit) was applied, followed by the addition of Substratechromogen mix (AEC Cromogeno kit). After washing, cells were mounted in glycerol/TBS 9:1 and observed using a Leitz microscope [46,47].

\section{Cytotoxicity studies}

The cytoxicity analysis was determined on in vitro cultured human OCs. PBMCs were plated in 96-well plates and, after 14 days, OCs were incubated with E. officinalis plant extracts for 3 days. Determinations of viable cells were performed after colorimetric assay with MTT (thiazolyl blue). The assay, based on the conversion of the yellow tetrazolium salt MTT to purple formazan crystals by metabolically active cells [56], provides a quantitative determination of viable cells. After $72 \mathrm{hr}$ of treatments in triplicate, $200 \mu \mathrm{L}$ of MTT was added to each well of cells, and the plate was incubated for $2 \mathrm{hr}$ at $37^{\circ}$. The medium was removed, and the MTT crystals were solubilized with 50\% DMF. Spectrophotometric absorbance of each sample was then measured at $570 \mathrm{~nm}$.

\section{Statistical analysis}

Data are presented as the mean \pm SEM from at least three independent experiments. Statistical analysis was performed by one-way analysis of variance followed by the Student's t-test. A P value $<0.005$ was considered statistically significant.

\section{Results \\ Effects of Emblica officinalis extracts on differentiation and viability of human primary osteoclasts}

Human primary osteoclasts were obtained from peripheral blood and cultured in complete D-MEM plus MCSF, PTH and RANKL for 14 days. OCs differentiation was tested by tartrate-acid resistant acid phosphatase (TRAP)positivity (Fig. 1) and metalloproteinase-9 (MMP-9) expression (data not shown). In order to test the effect of E. officinalis extracts on osteoclast differentiation, mature OCs (Fig. 1A) or monocytes during the two weeks of induction (Fig. 1B) were exposed to $0.5,5,50 \mu \mathrm{g} / \mathrm{ml}$ of plant extracts. The conditions used for these experiments 


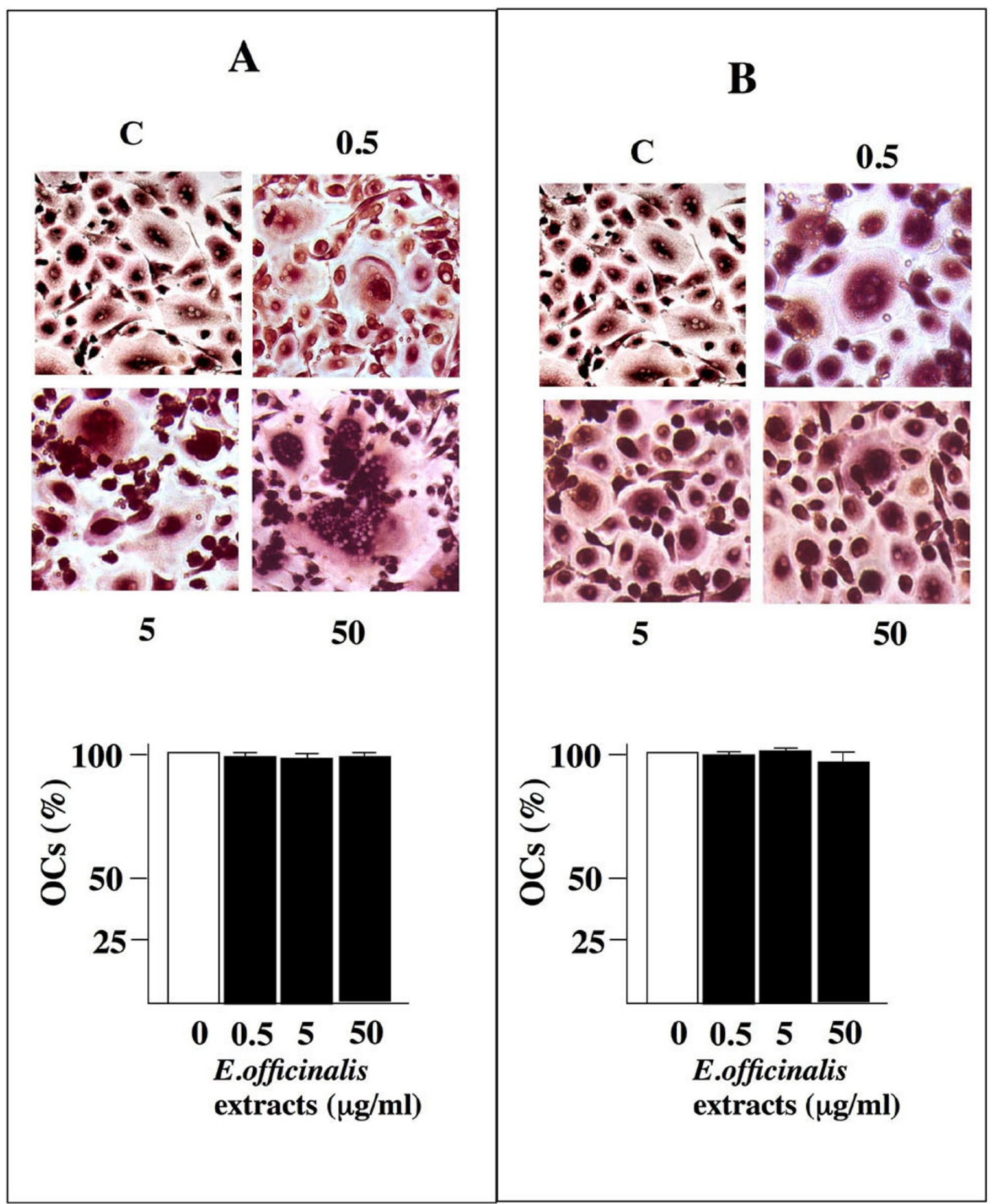

Figure I

TRAP staining analysis of human primary osteoclasts obtained after 14 days of culture in presence of $0.5,5$, and $50 \mu \mathrm{g} / \mathrm{ml}$ of Emblica officinalis extracts, as indicated (A); the same percentage of multinucleated TRAP-positive cells was obtained when mature osteoclasts were grown for 60 hours with the same amount of Emblica officinalis extracts (B). Cells were photographed at the $20 \times$ magnification. In the lower part of the panel data from five determinations are presented (average \pm SD). 
correspond to the concentrations of E. officinalis extracts leading to $50 \%$ of inhibition ( $\mathrm{IC}_{50}$ value) of cell growth, previously analyzed in different cell lines [55]. As reported in Figure 1, the presence of comparable levels of TRAPpositive cells cultured both in presence and in absence of E. officinalis extracts did not affect the process of osteoclastogenesis, at the concentrations employed. Quantitative data from three independent experiments are presented in the lower sides of Figure 1, demonstrating that treatment of the cultures with E. officinalis extracts does not have inhibitory effects on the development of TRAP-positive OCs. Cytotoxic effects of E. officinalis extracts were then analyzed. Human primary OCs were treated with increasing amount of E. officinalis extracts $(0.5-500 \mu \mathrm{g} / \mathrm{ml})$ for 72 hours and the viability of the cells was examined by the colorimetric MTT assay [56]. As shown in Figure 2, 0.5, 5 and $50 \mu \mathrm{g} / \mathrm{ml}$ of E. officinalis extracts did not cause any cytotoxic effect on the total cell population $(1-5 \%$ of which is constituted by OCs). Only E. officinalis extracts used at $500 \mu \mathrm{g} / \mathrm{ml}$ were found to induce a slight but not significant decrease of viability.

\section{Emblica officinalis extracts induce apoptosis of osteoclasts}

In a previous study we demonstrated that in different cell lines (K562, B-lymphoid Raji, T-lymphoid Jurkat and HEL cells) E. officinalis extracts retain an antiproliferative effect [55]. In the present paper we investigated osteoclasts in terms of apoptosis. To this aim, TUNEL test was performed on OCs after exposure, up to 60 hours, to $0.5,5$, and $50 \mu \mathrm{g} / \mathrm{ml}$ of E. officinalis extracts. As shown in the representative experiment reported in Figure 3 (panels A and B), a low but significant level of apoptosis (20\%) was induced by $0.5 \mu \mathrm{g} / \mathrm{ml}$ of extract; at 5 and $50 \mu \mathrm{g} / \mathrm{ml}$, a dramatic increase (respectively 50\% and 98\%) in TUNELpositive nuclei was observed. Table 1 reports summary data from three independent experiments, confirming the observation that 5 and $50 \mu \mathrm{g} / \mathrm{ml}$ of E. officinalis extracts consistently induce high levels of apoptosis of osteoclasts. Times of exposure shorter than 60 hours were also tested (24 and 48 hours) without obtaining significant differences from untreated cells (data not shown). These results were confirmed by immunocytochemical analysis of FAS receptor, a well known apoptosis-related protein [57], whose expression increased, as shown in Figure 3C, in OCs treated with E. officinalis extracts at all the concentrations used. When extracts from different medicinal plants, such as Satureja montana and Satureia hortensis were employed, no OCs apoptosis was induced (data not shown).

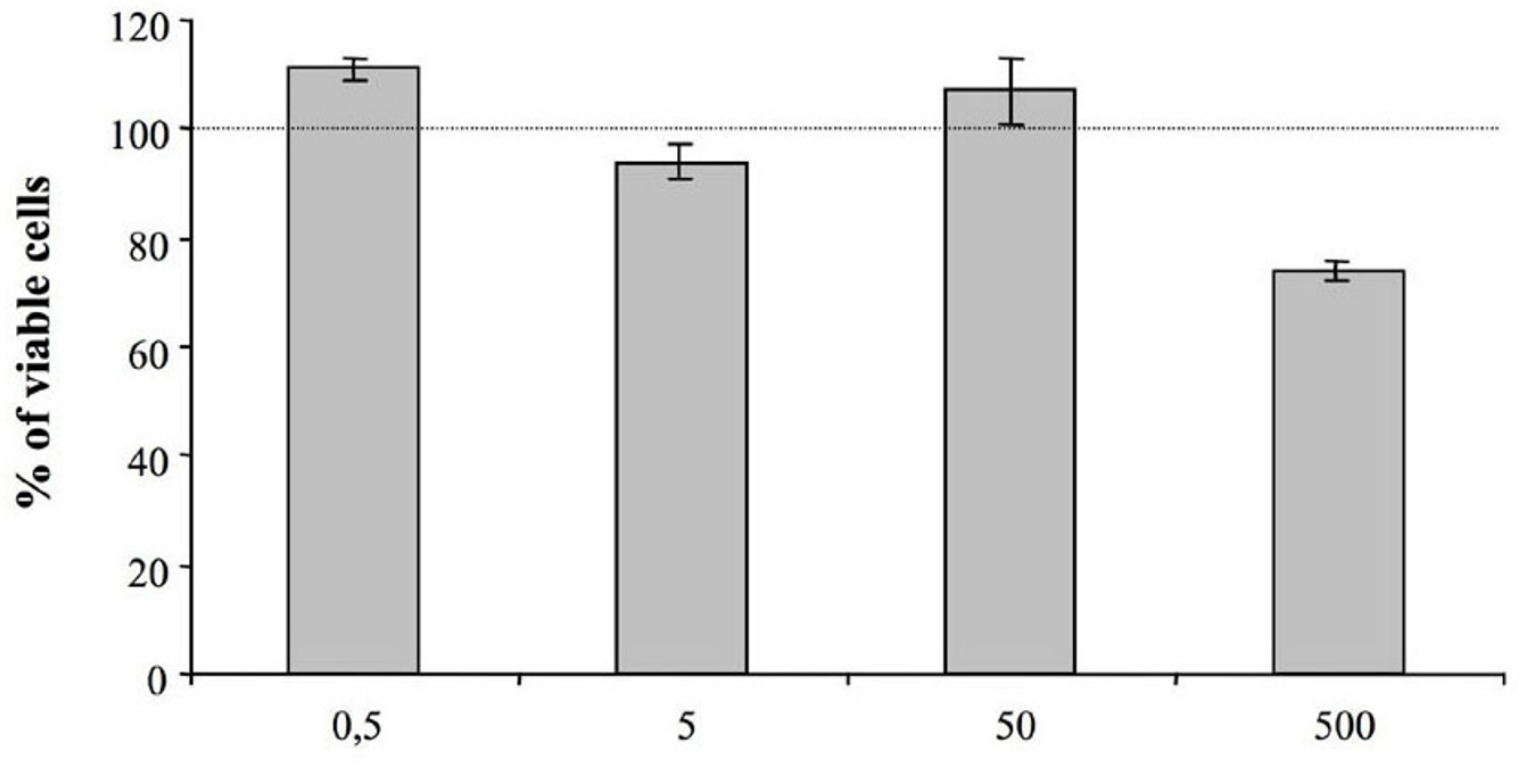

$(\mu \mathrm{g} / \mathrm{ml})$

\section{Figure 2}

Effect of different concentrations $(0.5-500 \mu \mathrm{g} / \mathrm{ml})$ of Emblica officinalis extract on cell survival of human primary osteoclast obtained by MTT colorimetric assay. Results are expressed as the percentage of surviving cells and are the average \pm SD of three independent experiments. The viability of controls only treated with vehicle $\left(\mathrm{H}_{2} \mathrm{O}\right)$ has been set as $100 \%$. 

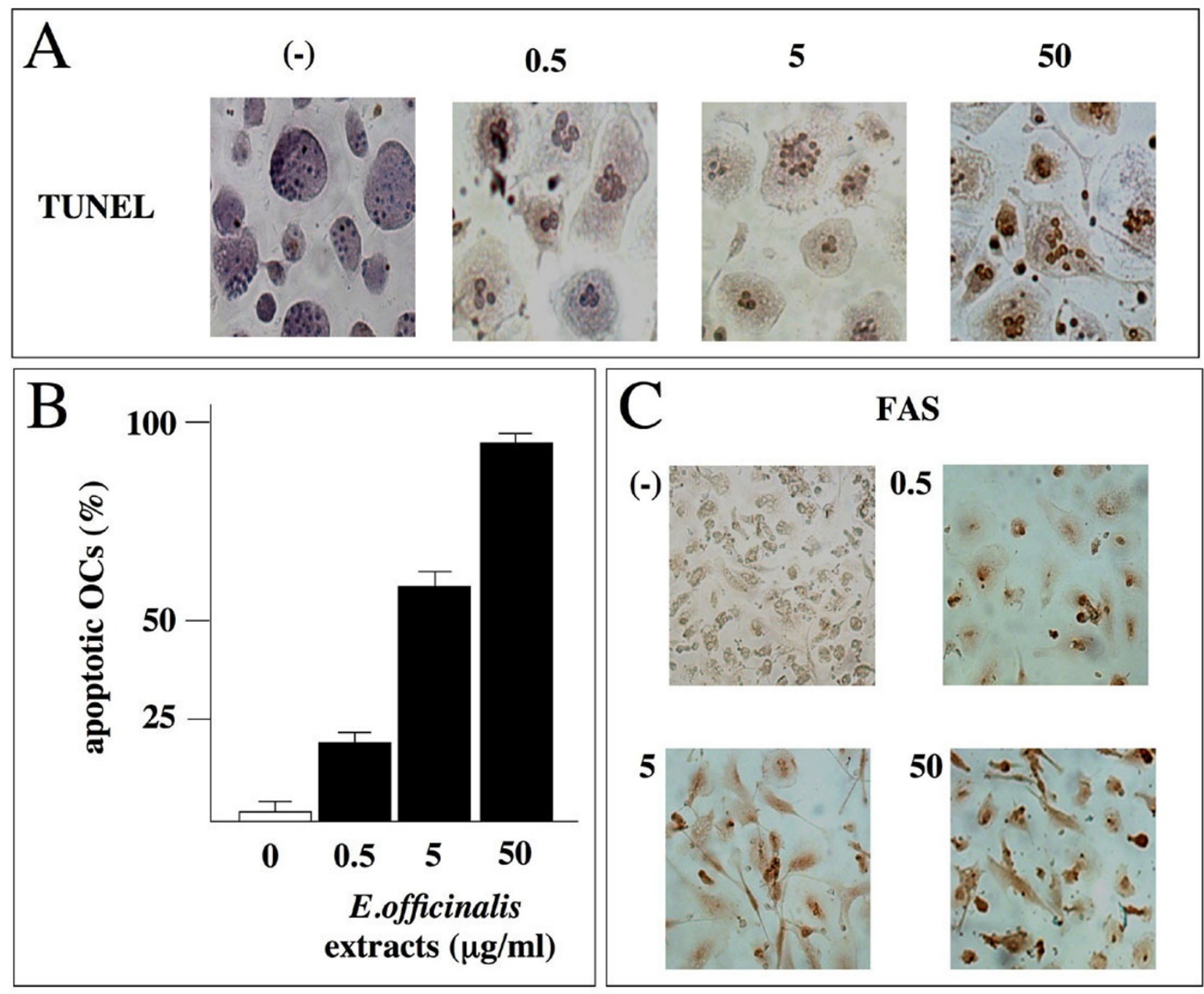

(-)

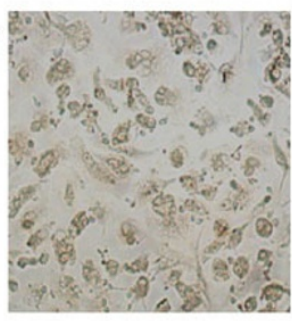

0.5

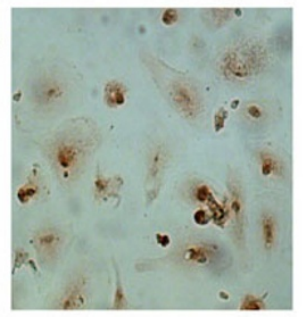

5

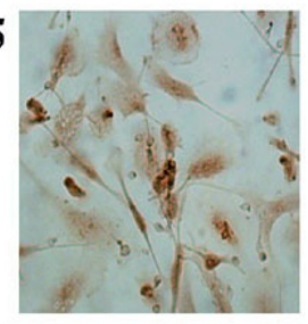

50

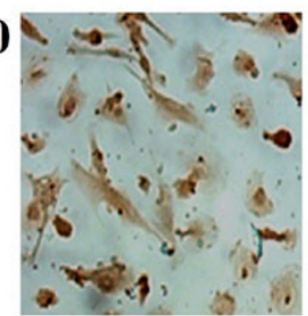

Figure 3

A, B. Detection of apoptosis by TUNEL assay in human primary osteoclasts. The presence of apoptotic OCs after treatment with $0.5,5,50 \mu \mathrm{g} / \mathrm{ml}$ of Emblica officinalis extract for 60 hours is shown in panel A. Brown color reaction indicates cells that underwent apoptosis. Quantitative results of the experiment shown in panel A are depicted in panel B (the data reported represent the average \pm SD of six independent determinations). C. Immunocytochemical analysis of FAS receptor expression levels in human primary osteoclasts subjected to the same experimental conditions reported in panel A. (-): control cells. Cells were photographed at the $20 \times$ magnification.

\section{In vitro effects of Emblica officinalis extracts on NF-kB transcription factor activity}

The ability of E. officinalis extracts to interfere with NF-kB binding to DNA was investigated, given that the transcription factor NF-kB plays a critical role in OCs activities by regulating the expression of a large number of OCs specific genes [48-50]. E. officinalis extracts were incubated in presence of $5 \mu \mathrm{g}$ of nuclear extracts from K562 cells with an oligonucleotide containing a cis element of the LTR of HIV-1 representing the DNA binding site for NF-kB. DNAprotein interactions were then analyzed by EMSA [51]. As reported in Figure 4, a dose dependent effect was observed, indicating the ability of E. officinalis extracts to completely inhibit NF-kB interaction with its cis element, when used at 100, 50, and $25 \mu \mathrm{g} /$ reaction. On the contrary, $100 \mu \mathrm{g}$ of $E$. officinalis extracts were not able to abolish the DNA-protein interactions of the transcription factor STAT-3 with its cis element (right side of Fig. 4) indicating a selectivity of the effects of E. officinalis extracts for NF-kB/DNA interactions. The sensitivity of NF-kB/ DNA interactions to E. officinalis extracts was demonstrated to be related to the type of plant extracts and not 
Table I: Apoptotic osteoclasts following treatment with E. officinalis extracts

\begin{tabular}{lllll}
\hline Experiment & \multicolumn{4}{l}{ E. officinalis extracts $(\mu \mathrm{g} / \mathrm{ml})$} \\
\hline & 0 & 0.5 & 5 & 50 \\
A & 2 & 20 & 33 & 97 \\
B & 3 & 15 & 58 & 98 \\
C & 2.5 & 55 & 65 & 99 \\
\hline
\end{tabular}

Detection of apoptosis of human primary OCs was performed by TUNEL assay. Treatment with $0.5,5,50 \mu \mathrm{g} / \mathrm{ml}$ of Emblica officinalis extracts was carried on for 60 hours. See Figure 3 for additional information.

to the extracting buffers, since no inhibitory effects were observed (a) with the extracting buffer and (b) other extracts from medicinal plants, such as Oroxylum indicum, Cuscuta reflexa, Paederia foetida, Hygrophilla auriculata, Ocimum sanctum (data not shown and Lampronti et al.) [57].

In order to determine whether E. officinalis extracts affect NF-kB dependent biological activity in OCs, we have evaluated the effects of the plant extracts on the expression of IL-6, a target gene of NF-kB transcription factors $[58,59]$.
Immunocytochemical analysis, reported in Figure 5, clearly shows a significant decrease of IL-6 levels in OCs treated with $5-50 \mu \mathrm{g} / \mathrm{ml}$ of E. officinalis extracts after comparison to control untreated cells.

\section{Discussion}

The present study suggests the employment of primary cultures of human osteoclasts as a tool to test the potential interest of extracts of Emblica officinalis fruits in the experimental therapy of human pathologies associated with bone loss, including osteoarthritis and osteoporosis. The possible use of natural products, including plant extracts and nutriaceuticals, is under debate. A systematic review of the scientific evidence supporting the hypothesis that nutrition can improve the symptoms of declared osteoarthritis has been recently published [60]. In addition, the possible use of medicinal plant extracts or single products derived from them for preventing or treating experimentally rheumatoid arthritis has been reported [31-33]. In this respect, one of the best example is Turmeric, derived from the plant Curcuma longa, a gold-colored spice commonly used in the Indian subcontinent in Ayurvedic medicine as a treatment for inflammatory disorders, including

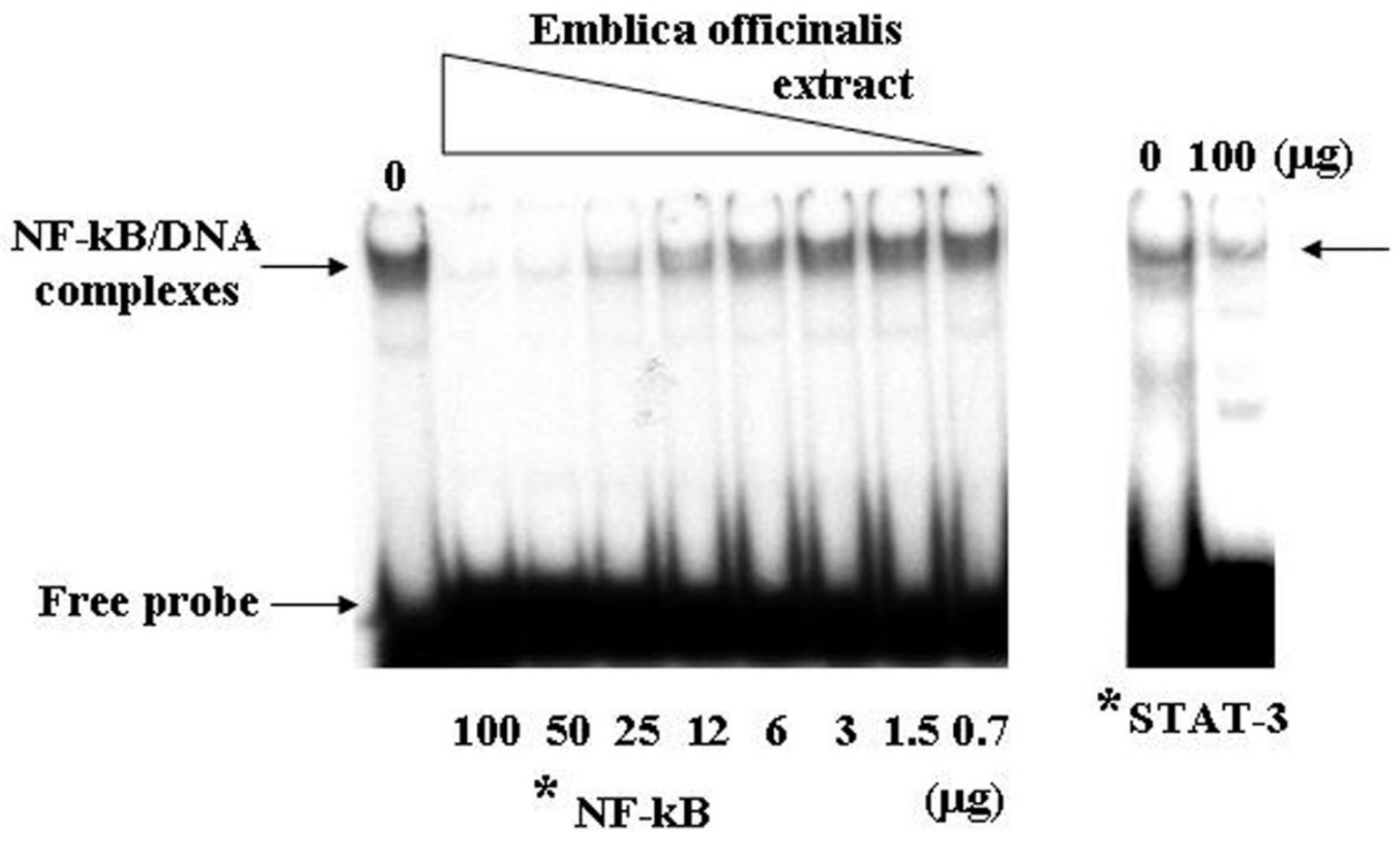

Figure 4

Analysis by electrophoretic mobility shift assay of the effects of Emblica officinalis extracts on NF-kB DNA binding activity. Nuclear extracts from the K562 cell line were incubated with ${ }^{32 P}$-labelled oligonucleotides (*) NF-kB and STAT-3, in the presence of different amounts $(100,50,25,12.5,6,3,1.5,1 \mu \mathrm{g})$ of Emblica officinalis extracts. Protein/DNA complexes and free probe are indicated by arrows. 
$(-)$

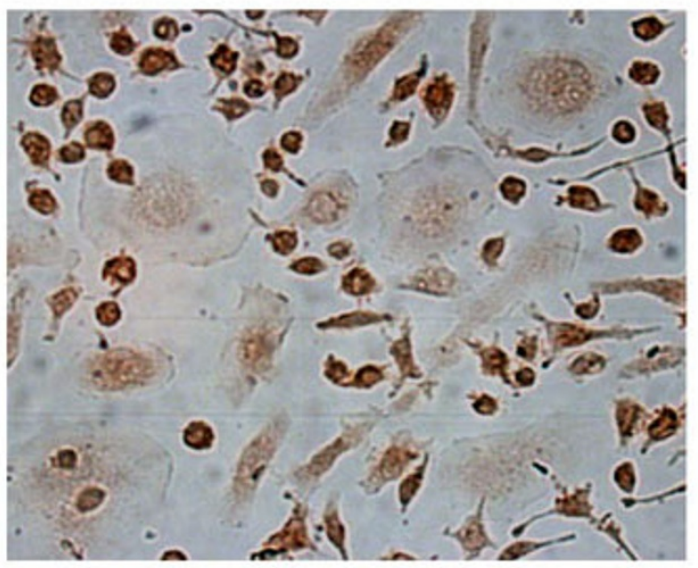

\section{5}

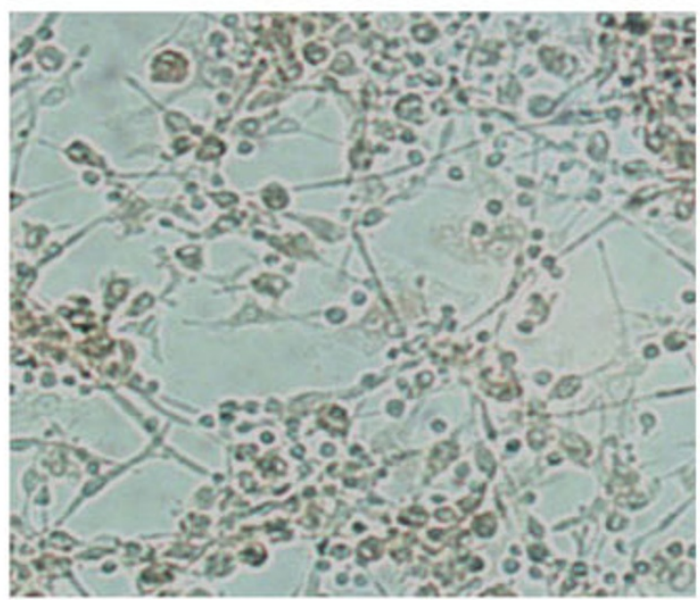

0.5

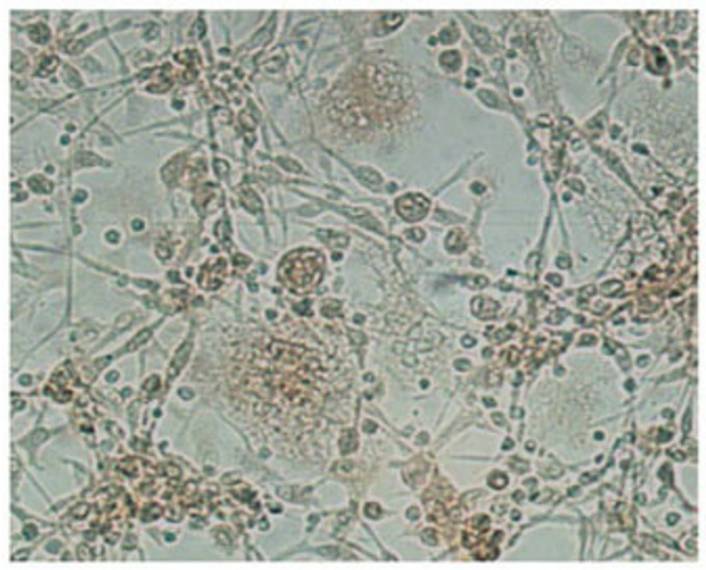

50

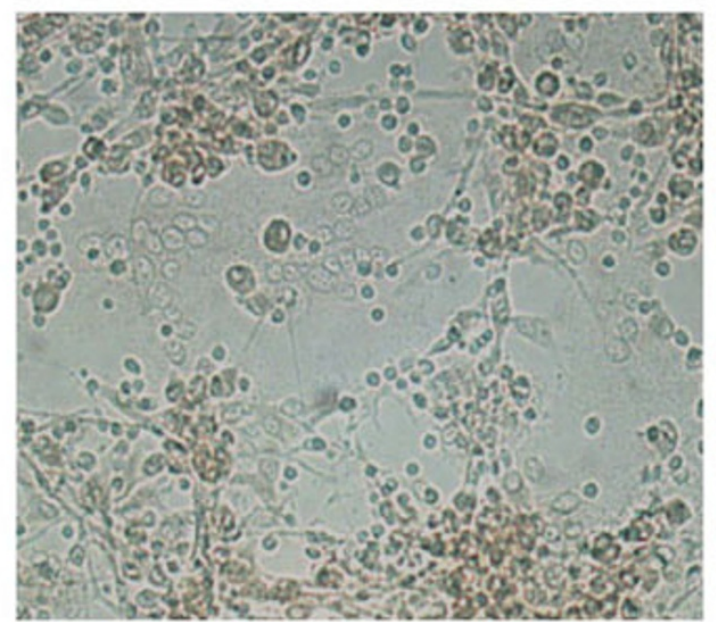

Figure 5

Different expression of IL-6 in human primary osteoclasts analyzed by immunocytochemistry with specific antibody after incubation for $\mathbf{6 0}$ hours in the absence $(-)$, or in the presence of $0.5,5$ and $50 \mu \mathrm{g} / \mathrm{ml}$ of Emblica officinalis extracts. Cells were photographed at the $20 \times$ magnification.

arthritis. On the basis of this traditional usage, dietary supplements containing turmeric rhizome and curcuminoid-containing turmeric extracts are used in the western world for arthritis treatment and prevention [31].

Emblica officinalis is reported to have antitumor activity $[42,45,54]$ together with beneficial effects in gynecological, hepatic, respiratory and skin $[43,44]$ disorders. However, the biological activity of Emblica officinalis extracts of possible interest for treatment of arthritis and osteoporosis have not yet been reported. To verify this effect in vitro different experimental approaches should be used in parallel, including analysis of possible positive effects on osteoblastogenesis and negative effects on osteoclastogen- esis. In fact, increase of bone formation, leading to antiosteoporotic and anti-osteoarthritis activity, could be obtained by induction of osteoblast activity, inhibition of osteoclast bone resorption, or both of these effects. In previous studies [34-36] osteoblast-like UMR106 cells, derived from a rat osteogenic sarcoma, were used to screen drugs and plant extracts for stimulation of bone formation.

The aim of our study was to determine the activity of $E$. officinalis extracts on osteoclasts, using primary OCs of human origin isolated from peripheral blood and incubated for different length of time and with different amounts of E. officinalis extracts. The analysis of cellular 
viability and apoptosis demonstrates that these plant extracts do not have any cytotoxic effect, even at a concentration of $500 \mu \mathrm{g} / \mathrm{ml}$, still inducing significant level of apoptosis. This effect was confirmed by the finding of increasing levels of FAS receptor after treatment with both high and low concentrations of E. officinalis extracts. Hence, we conclude that E. officinalis extracts are strong inducers of the apoptotic pathway of primary human osteoclasts.

Since the transcription factor NF-kB has been reported to be important for the expression of several osteoclast-specific genes, we verified whether E. officinalis extracts were able to inhibit the biological activity of this factor. An electrophoretic mobility shift assay demonstrated that NF-kB/DNA complexes are inhibited after incubation of nuclear DNA-binding proteins with increasing amounts of E. officinalis extracts. Accordingly, when the analysis was carried on cultured OCs, high levels of inhibition of IL-6, a NF-kB modulated protein were found, further demonstrating that NF-kB dependent biological functions are impaired following treatment with E. officinalis extracts. On the basis of this experimental evidence we propose that the pro-apoptotic action of E. officinalis extracts on osteoclasts could be mediated, at least in part, by interfering with NF-kB activity.

Interestingly, the effects on human OCs of E. officinalis extracts are similar to those reported for other inhibitors of NF-kB functions, such as biphenylcarboxylic acid butanediol ester (ABD56) [61] and genistein [62]. In addition the effects of $E$. officinalis extracts are almost over imposable to those of a decoy double-stranded oligonucleotide mimicking NF-kB binding sites [46]. Similarly to this decoy oligonucleotide, E. officinalis extracts, at the concentrations employed, induce OCs apoptosis without inhibiting osteoclastogenesis. An effect of E. officinalis at higher concentrations cannot be excluded; however, at these levels a certain cytotoxicity (see Figure 2) renders difficult the discrimination between a possible inhibitory effect on OCs differentiation and an overall antiproliferative activity.

Finally, we like to point out that our results are based on an in vitro approach, and specificity in vivo of the effects here described should be carefully determined, since the transcription factor NF-kB is also important for other cellular systems, including macrophages, that when exposed to the extracts may overwhelm the effects on osteoclasts. In this respect, several in vivo systems suitable for testing inducers of OCs apoptosis are now available [63-65].

\section{Conclusion}

The data here reported on the effects of E. officinalis extracts on mature human osteoclasts suggest the possible use of this medicinal plant as a therapeutic tools against different forms of arthritis and osteoporosis, improving the activity of already employed drugs. In addition, E. officinalis extracts could be analyzed to identify single compounds responsible for the biological activity identified.

\section{Abbreviations}

OCs: osteoclasts; TRAP: tartrate-resistant acid phosphatase; NF-kB: nuclear factor kappa-B; RANKL: receptor activator of NF-kB ligand; PBMCs: peripheral blood mononuclear cells; PTH: parathyroid hormone; MCSF: macrophage colony-stimulating factor; MTT: 3-(4,5Dimethylthiazol-2-yl)-2,5-diphenyltetrazolium bromide.

\section{Competing interests}

The authors declare that they have no competing interests.

\section{Authors' contributions}

LP developed the culture of osteoclasts from the peripheral blood; IL characterized the E. officinalis extracts with respect to effects of cell growth; $\mathrm{MB}$ performed gel shift experiments using nuclear factors and oligonucleotides mimicking the NF-kB binding sites; MTHK isolated the the E. officinalis extracts; RP designed the experiments with the osteoclasts cultures; RG wrote the paper and coordinated the experiments. All authors read and approved the final manuscript.

\section{Acknowledgements}

R.G. is funded by CIB (Consorzio Interuniversitario di Biotecnologie, Italy), AIRC (Associazione Italiana Ricerca sul Cancro), AVTL (Associazione Veneta per la Lotta alla Talassemia, Italy), SPINNER e PRIITT (EU, Obiettivo 2), Fondazione Cassa di Risparmio di Padova e Rovigo, STAMINA Project of Ferrara University and UE ITHANET Project. We would like to thank Dr. Amanda J. Neville (Department of Experimental and Diagnostic Medicine, Section of Medical Genetics) for her contribution in revising the text.

\section{References}

I. Szekanecz Z, Koch AE: Macrophages and their products in rheumatoid arthritis. Curr Opin Rheumatol 2007, 19:289-95.

2. Hadjidakis DJ, Androulakis II: Bone remodeling. Ann N Y Acad Sci 2006, I092:385-96.

3. Giuliani N, Morandi F, Tagliaferri S, Rizzoli V: Targeting pathways mediating bone disease. Curr Pharm Biotechnol 2006, 7:423-9.

4. Blair HC, Zaidi M: Osteoclastic differentiation and function regulated by old and new pathways. Rev Endocr Metab Disord 2006, 7:23-32.

5. Ochi S, Shinohara M, Sato K, Gober HJ, Koga T, Kodama T, Takai T, Miyasaka N, Takayanagi $\mathrm{H}$ : Pathological role of osteoclast costimulation in arthritis-induced bone loss. Proc Natl Acad Sci USA 2007, 104: I1394-11399.

6. Schett G: Cells of the synovium in rheumatoid arthritis. Osteoclasts. Arthritis Res Ther 2007, 9:203.

7. Haynes DR: Emerging and future therapies for the treatment of bone loss associated with chronic inflammation. Inflammopharmacology 2006, I4:193-7.

8. Tremoulet AH, Albani S: Novel therapies for rheumatoid arthritis. Expert Opin Investig Drugs 2006, I5:1427-4I.

9. Boyce BF, Schwarz EM, Xing L: Osteoclast precursors: cytokinestimulated immunomodulators of inflammatory bone disease. Curr Opin Rheumatol 2006, I 8:427-32. 
10. Sato K, Takayanagi H: Osteoclasts, rheumatoid arthritis, and osteoimmunology. Curr Opin Rheumatol 2006, I8:419-26.

II. Teitelbaum SL: Osteoclasts; culprits in inflammatory osteolysis. Arthritis Res Ther 2006, 8:20I.

12. Kim KW, Cho ML, Lee SH, Oh HJ, Kang CM, Ju JH, Min SY, Cho YG, Park SH, Kim HY: Human rheumatoid synovial fibroblasts promote osteoclastogenic activity by activating RANKL via TLR-2 and TLR-4 activation. Immunol Lett 2007, I I 0:54-64.

13. Colucci S, Brunetti G, Cantatore FP, Oranger A, Mori G, Quarta L, Cirulli N, Mancini L, Corrado A, Grassi FR, Grano M: Lymphocytes and synovial fluid fibroblasts support osteoclastogenesis through RANKL, TNFalpha, and IL-7 in an in vitro model derived from human psoriatic arthritis. J Pathol 2007, 2 I 2:47-55

14. Tanishima S, Kishimoto Y, Fukata S, Mizumura H, Hagino H, Teshima $\mathrm{R}$ : Minodronic acid influences receptor activator of nuclear factor kB ligand expression and suppresses bone resorption by osteoclasts in rats with collagen-induced arthritis. Mod Rheumatol 2007, 17:198-205.

15. Kitahara K, Kawai S: Cyclosporine and tacrolimus for the treatment of rheumatoid arthritis. Curr Opin Rheumatol 2007, 1 9:238-45

16. Gillespie MT: Impact of cytokines and T lymphocytes upon osteoclast differentiation and function. Arthritis Res Ther 2007 9:103.

17. Suematsu A, Tajiri Y, Nakashima T, Taka J, Ochi S, Oda H, Nakamura $\mathrm{K}$, Tanaka S, Takayanagi H: Scientific basis for the efficacy of combined use of antirheumatic drugs against bone destruction in rheumatoid arthritis. Mod Rheumatol 2007, 17:17-23.

18. Shu G, Yamamoto K, Nagashima M: Differences in osteoclast formation between proximal and distal tibial osteoporosis in rats with adjuvant arthritis: inhibitory effects of bisphosphonates on osteoclasts. Mod Rheumatol 2006, 16:343-9.

19. Haynes DR: Emerging and future therapies for the treatment of bone loss associated with chronic inflammation. Inflammopharmacology 2006, 14:193-7.

20. Verdrengh M, Carlsten H, Ohlsson C, Tarkowski A: Addition of bisphosphonate to antibiotic and anti-inflammatory treatment reduces bone resorption in experimental Staphylococcus aureus-induced arthritis. J Orthop Res 2007, 25:304-10.

21. Croom KF, Scott LJ: Intravenous ibandronate: in the treatment of osteoporosis. Drugs 2006, 66: I593-60I.

22. Chapurlat RD, Delmas PD: Drug insight: Bisphosphonates for postmenopausal osteoporosis. Nat Clin Pract Endocrinol Metab 2006, 2:21I-9.

23. Manette C, Collette J, Sarlet N, Tancredi A, Zegels B, Reginster JY Comprehensive therapy in osteoporosis using a single drug: from ADFR to strontium ranelate. Curr Med Chem 2006, I 3:1585-90

24. Cicek M, Oursler MJ: Breast cancer bone metastasis and current small therapeutics. Cancer Metastasis Rev 2006, 25:635-44.

25. Lipton A: Future treatment of bone metastases. Clin Cancer Res 2006, I 2(20 Pt 2):6305s-6308s.

26. Bagi CM: Targeting of therapeutic agents to bone to treat metastatic cancer. Adv Drug Deliv Rev 2005, 57:995-1010.

27. Kanakis I, Kousidou OCh, Karamanos NK: In vitro and in vivo antiresorptive effects of bisphosphonates in metastatic bone disease. In Vivo 2005, 19:3।I-8.

28. Putnam SE, Scutt AM, Bicknell K, Priestley CM, Williamson EM: Natural products as alternative treatments for metabolic bone disorders and for maintenance of bone health. Phytother Res 2007, $21: 99-112$.

29. New SA: Intake of fruit and vegetables: implications for bone health. Proc Nutr Soc 2003, 62:889-99.

30. Hidaka S, Okamoto $Y$, Yamada $Y$, Kon $Y$, Kimura TA: Japanese herbal medicine, Chujo-to, has a beneficial effect on osteoporosis in rats. Phytother Res 1999, 13:14-9.

31. Funk JL, Oyarzo JN, Frye JB, Chen G, Lantz RC, Jolad SD, Solyom AM, Timmermann BN: Turmeric extracts containing curcuminoids prevent experimental rheumatoid arthritis. I Nat Prod 2006 69:35I-5.

32. Ramprasath VR, Shanthi P, Sachdanandam P: Curative effect of Semecarpus anacardium Linn. nut milk extract against adjuvant arthritis - with special reference to bone metabolism. Chem Biol Interact 2006, 160:183-92.
33. Sohail MT, Chaudhry MI, Usman MK, Mian T, Ishaq MN: Efficacy and tolerance of atrisin in degenerative and inflammatory joint disorders. Phytother Res 2005, 19:365-8.

34. Yin J, Tezuka Y, Kouda K, Le Tran Q, Miyahara T, Chen Y, Kadota S: Antiosteporotic activity of the water extract of Dioscorea spongiosa. Biol Pharm Bull 2004, 27:583-586.

35. Wang D, Li F, Jiang Z: Osteoblastic proliferation stimulating activity of Psoralea corylifollia extracts and two of its flavonoids. Planta Med 200I, 67:748-749.

36. Meng F, Xiong Z, Sun Y, Li F: Coumarins from Cidium monnieri (L.) and their proliferation stimulating activity on osteoblastlike UMR 106 cells. Pharmazie 2004, 59:643-645.

37. Anila L, Vijayalakshmi NR: Flavonoids from Emblica officinalis and Mangifera indica, effectiveness for dyslipidemia. J Ethnopharmacol 2002, 79:81-87.

38. Thakur CP, Mandal K: Effect of Emblica officinalis on cholesterol-induced atherosclerosis in rabbits Indian. J Med Res 1984, 79:142-146.

39. Bhattacharya A, Kumar M, Ghosal S, Bhattacharya SK: Effect of bioactive tannoid principles of Emblica officinalis on iron-indued hepatic toxicity in rats. Phytomedicine 2000, 7:173-175.

40. Ahmad I, Mehmood Z, Mohammad F: Screening of some Indian medicinal plants for their antimicrobial properties. J Ethnopharmacol 1998, 62:183-93.

4I. Asmawi MZ, Kankaanranta H, Moilanen E, Vapaatalo H: Anti-inflammatory activities of Emblica officinalis Gaertn leaf extracts. Pharm Pharmacol 1993, 45:58I-584

42. Jeena KJ, Kuttan G, Kuttan R: Antitumor activity of Emblica officinalis. J of Ethnoph 200I, 75:65-69.

43. Sancheti G, Jindal A, Kumari R, Goyal PK: Chemopreventive action of Emblica officinalis on skin carcinogenesis in mice. Asian Pac J Cancer Prev 2005, 6: 197-20 I.

44. Sultana S, Ahmad S, Khan N, Jahangir T: Effect of Emblica officinalis (Gaertn) on CCl4 induced hepatic toxicity and DNA synthesis in Wistar rats. Indian J Exp Biol 2005, 43:430-6.

45. Scartezzini P, Antognoni F, Raggi MA, Poli F, Sabbioni C: Vitamin C content and antioxidant activity of the fruit and of the Ayurvedic preparation of Emblica officinalis Gaertn. J Ethnopharmacology 2006, 104: I 13-8.

46. Penolazzi L, Lambertini E, Borgatti M, Piva R, Cozzani M, Giovannini I, Naccari R, Siciliani G, Gambari R: Decoy oligodeoxynucleotides targeting NF-kappaB transcription factors: induction of apoptosis in human primary osteoclasts. Biochem Pharmacol 2003, 66: II89-98.

47. Piva R, Penolazzi L, Lambertini E, Giordano S, Gambari R: Induction of apoptosis of human primary osteoclasts treated with a transcription factor decoy mimicking a promoter region of estrogen receptor alpha. Apoptosis 2005, 10:1079-94.

48. Borgatti M, Lampronti I, Romanelli A, Pedone C, Saviano M, Bianchi N, Mischiati C, Gambari R: Transcription factor decoy molecules based on a peptide nucleic acid (PNA)-DNA chimera mimicking SpI binding sites. J Biol Chem 2003, 278:7500-9.

49. Piva R, Penolazzi L, Zennaro M, Bianchini E, Magri E, Borgatti M, Lampronti I, Lambertini E, Tavanti E, Gambari R: Induction of apoptosis of osteoclasts by targeting transcription factors with decoy molecules. Ann N Y Acad Sci 2006, 1091:509-16.

50. Park BK, Zhang H, Zeng Q, Dai J, Keller ET, Giordano T, Gu K, Shah V, Pei L, Zarbo RJ, McCauley L, Shi S, Chen S, Wang CY: NF-kappaB in breast cancer cells promotes osteolytic bone metastasis by inducing osteoclastogenesis via GM-CSF. Nat Med 2007, 13:62-9.

5I. Yamashita T, Yao Z, Li F, Zhang O, Badell IR, Schwarz EM, Takeshita S, Wagner EF, Noda M, Matsuo K, Xing L, Boyce BF: NF-\{kappa\}B p50 and p52 Regulate Receptor Activator of NF-\{kappa\}B Ligand (RANKL) and Tumor Necrosis Factor-induced Osteoclast Precursor Differentiation by Activating c-Fos and NFATcl. J Biol Chem 2007, 282:|8245-53.

52. Matsuzaki K, Katayama K, Takahashi Y, Nakamura I, Udagawa N, Tsurukai T, Nishinakamura R, Toyama $Y$, Yabe $Y$, Hori M, Takahashi N, Suda T: Human osteoclast-like cells are formed from peripheral blood mononuclear cells in a coculture with SaOS-2 cells transfected with the parathyroid hormone (PTH)/PTHrelated protein receptor gene. Endocrinology 1999, I 40:925-32.

53. Villanova I, Townsend PA, Uhlmann E, Knolle J, Peyman A, Amling M, Baron R, Horton MA, Teti A: Oligodeoxynucleotide targeted to the alphav gene inhibits alphav integrin synthesis, impairs 
osteoclast function, and activates intracellular signals to apoptosis. J Bone Miner Res 1999, 14:1867-79.

54. Khan MTH, Lampronti I, Martello D, Bianchi N, Jabbar S, Choudhuri SMK, Datta BK, Gambari R: Identification of pyrogallol as an antiproliferative compound present in extracts from the medicinal plant Emblica Officinalis: effects on in vitro cell growth of human tumor cell lines. Int J Oncol 2002, 20: I87-1 92.

55. Lampronti I, Martello D, Bianchi N, Borgatti M, Lambertini E, Piva R, Jabbar S, Shahabuddin Kabir Choudhuri M, Tareq Hassan Khan M, Gambari R: In vitro antiproliferative effects on human tumor cell lines of extracts from the Bangladeshi medicinal plant Aegle marmelos Correa. Phytomedicine 2003, 10:300-308.

56. Denizot F, Lang RJ: Rapid colorimetric assay for cell growth and survival. Modifications to the tetrazolium dye procedure giving improved sensitivity and reliability. Immunol Meth 1986, 22:27I-277.

57. Lampronti I, Khan MTH, Borgatti M, Bianchi N, Gambari R: Inhibitory effects of Bangladeshi medicinal plant extracts on interaction teween transcription factors and target DNA sequences. Evidence-based Complementary and Alternative Medicine 2007.

58. Pritts T, Hungness E, Wang Q, Robb B, Hershko D, Hasselgren PO: Mucosal and enterocyte IL-6 production during sepsis and endotoxemia - role of transcription factors and regulation by the stress response. Am J Surg 2002, 183:372-83.

59. Domingo-Domenech J, Oliva C, Rovira A, Codony-Servat J, Bosch M, Filella X, Montagut C, Tapia M, Campas C, Dang L, Rolfe M, Ross JS, Gascon P, Albanell J, Mellado B: Interleukin 6, a nuclear factorkappaB target, predicts resistance to docetaxel in hormoneindependent prostate cancer and nuclear factor-kappaB inhibition by PS- I I 45 enhances docetaxel antitumor activity. Clin Cancer Res 2006, 12:5578-86.

60. Ameye LG, Chee WS: Osteoarthritis and nutrition. From nutraceuticals to functional foods: a systematic review of the scientific evidence. Arthritis Res Ther 2006, 8:RI 27.

6I. Idris A, Mrak E, Greig I, Guidobono F, Ralston SH, van't Hof R: ABD56 causes osteoclast apoptosis by inhibiting the NFkappaB and ERK pathways. Biochem Biophys Res Commun 2008, 371:94-8.

62. Uchiyama S, Yamaguchi M: Genistein and zinc synergistically stimulate apoptotic cell death and suppress RANKL signaling-related gene expression in osteoclastic cells. / Cell Biochem 2007, I 01:529-42.

63. Do SH, Lee JW, Jeong WI, Chung JY, Park SJ, Hong IH, Jeon SK, Lee IS, Jeong KS: Bone-protecting effect of Rubus coreanus by dual regulation of osteoblasts and osteoclasts. Menopause 2008, 15:676-83.

64. Faloni AP, Sasso-Cerri E, Katchburian E, Cerri PS: Decrease in the number and apoptosis of alveolar bone osteoclasts in estrogen-treated rats. J Periodontal Res 2007, 42: 193-20I.

65. Penolazzi L, Magri E, Lambertini E, Bianchini E, Piva R, Gambari R: "In vivo" local transfection of a cis element decoy mimicking an estrogen receptor alpha gene promoter region induces apoptosis of osteoclasts following application of orthodontic forces to rat teeth. Apoptosis 2006, I I:1653-6.

\section{Pre-publication history}

The pre-publication history for this paper can be accessed here:

http://www.biomedcentral.com/1472-6882/8/59/prepub Publish with Biomed Central and every
scientist can read your work free of charge

"BioMed Central will be the most significant development for disseminating the results of biomedical research in our lifetime. "

Sir Paul Nurse, Cancer Research UK

Your research papers will be:

- available free of charge to the entire biomedical community

- peer reviewed and published immediately upon acceptance

- cited in PubMed and archived on PubMed Central

- yours - you keep the copyright
BioMedcentral 